\title{
Patrón nodular perilinfático
}

\section{Random nodular pattern}

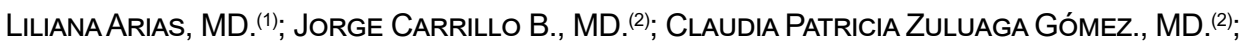
MELISSA KALLMANN S., MD. ${ }^{(3)}$

(1)Radiología - Hospital Santa Clara y Hospital Universitario San Ignacio, Bogotá, Colombia.

${ }^{(2)}$ Radiología - Hospital Universitario Mayor - Mederi, Bogotá, Colombia.

${ }^{(3)}$ Medicina Interna - Radiología - Universidad del Rosario, Bogotá, Colombia.

Correspondencia: Claudia Patricia Zuluaga Gómez, correo electrónico: patozulua@ gmail.com

Recibido: 15/01/16. Aceptado: 25/01/16.
El término "nódulo" se utiliza para describir una opacidad pulmonar redondeada, bien o mal definida, menor de $3 \mathrm{~cm}$ de diámetro. El análisis de las lesiones nodulares del parénquima pulmonar debe incluir tamaño, contornos, densidad y localización. Los nódulos menores de $10 \mathrm{~mm}$ de diámetro se consideran pequeños $(1,2)$. La sociedad Fleishner define como micronódulos a los nódulos menores de $3 \mathrm{~mm}$ de diámetro. En general, el término de patrón nodular hace referencia a lesiones nodulares pequeñas, múltiples, en el parénquima pulmonar. La localización de los nódulos en relación con las estructuras del lobulillo pulmonar secundario permite estrechar el diagnóstico diferencial y categoriza el patrón nodular en: perilinfático, aleatorio y centrilobulillar (1).

Los nódulos de distribución perilinfática pueden localizarse en relación con el intersticio peribroncovascular perihiliar, los septos interlobulillares, las regiones subpleurales y el intersticio centrilobulillar. Característicamente los pacientes con patrón nodular perilinfático presentan nodularidad subpleural, nodularidad perivascular y arrosariamiento de las cisuras. En general, la distribución de los nódulos es "parcheada", con áreas de pulmón respetadas (1).
En el diagnóstico diferencial del patrón nodular perilinfático deben considerarse entidades granulomatosas (sarcoidosis), neoplásicas (carcinomatosis linfangítica) y enfermedades linfoproliferativas (tabla 1).

\section{Sarcoidosis}

El patrón nodular perilinfático se presenta en el $90 \%$ de pacientes con sarcoidosis. En general, los nódulos se localizan en el intersticio peribroncovascular perihiliar y el intersticio subpleural. Son de tamaño variable, de contornos bien definidos, pueden coalescer, y predominan en los lóbulos superiores. Otras alteraciones presentes en la tomografía computarizada de pacientes con sarcoidosis incluyen: adenomegalias paratraqueales e hiliares bilaterales, nódulos grandes, áreas de vidrio esmerilado/ consolidación y cambios fibróticos con opacidades reticulares, distorsión de la arquitectura pulmonar y bronquiectasias de tracción $(20 \%$ de pacientes) (3) (figura 1).

Tabla 1. Diagnósticos diferenciales.

Amiloidosis difusa

Neumonía intersticial linfocítica en pacientes con: disproteinemia, enfermedades autoinmunes, VIH

Sarcoma de Kaposi 

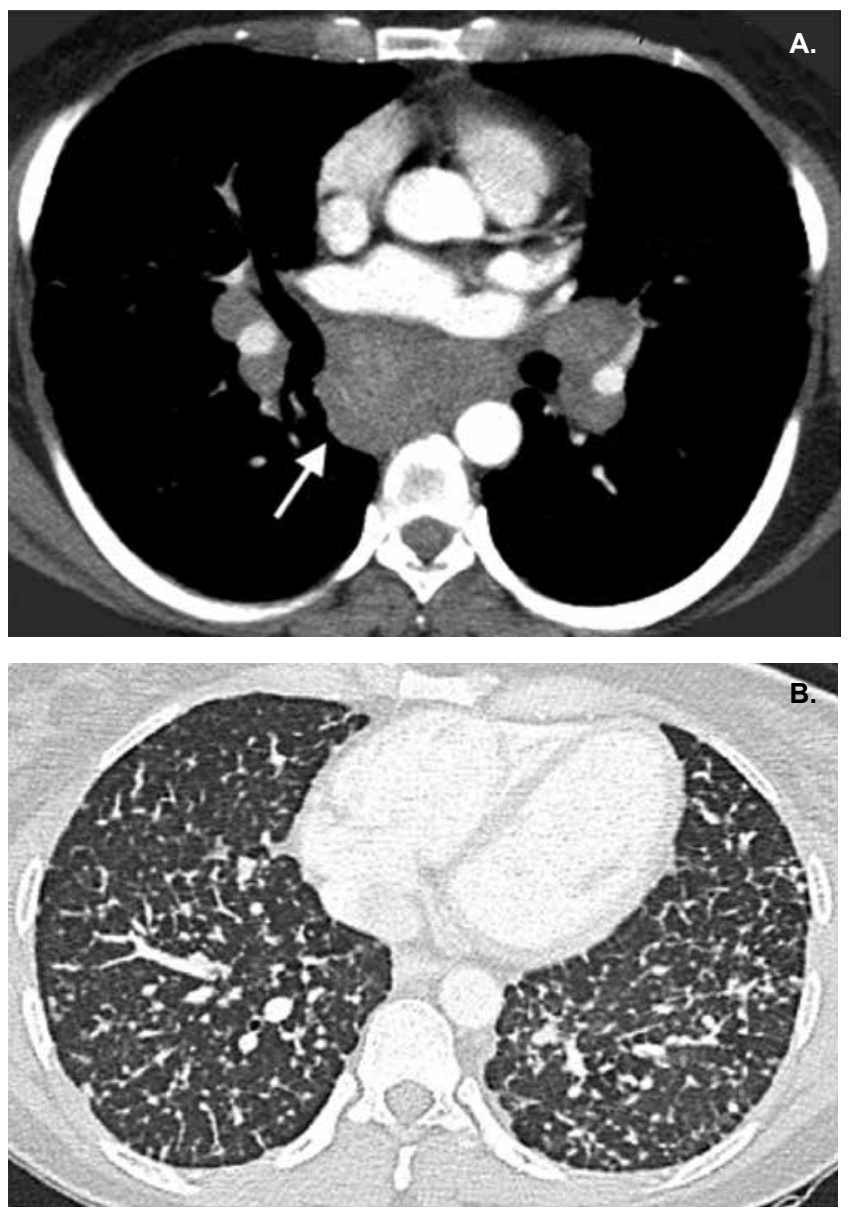

Figura 1. Sarcoidosis. A. Corte axial en ventana de mediastino. Adenomegalias mediastinales hiliares y subcarinales. Flecha blanca. B. Corte axial en ventana de pulmón. Nodularidad del intersticio peribroncovascular e interlobulillar. Nódulos pequeños subpleurales de escasa profusión.

\section{Carcinomatosis linfangítica}

El patrón nodular perilinfático asociado a diseminación tumoral linfangítica se asocia a engrosamiento del intersticio peribroncovascular y engrosamiento de los septos interlobulillares. El aspecto arrosariado de los septos se relaciona con tumor en los capilares pulmonares, linfáticos e intersticio periférico. La distribución de las alteraciones es variable: unilateral, simétrica, bilateral o en " parches” (figura 2).

Otras alteraciones en los estudios de imágenes de pacientes con carcinomatosis linfangítica incluyen: nódulos centrilobulillares (por alteración del intersticio peribroncovascular centrilobulillar),
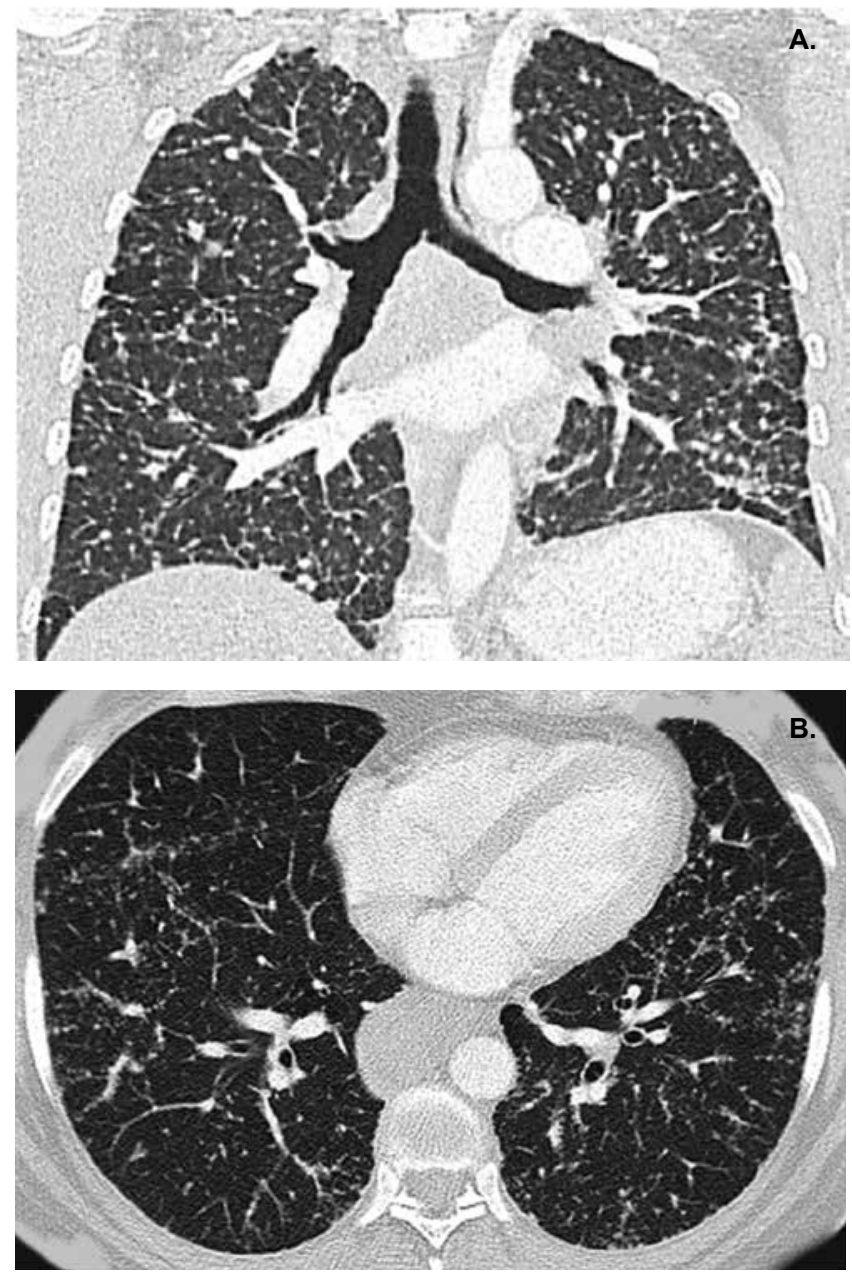

Figura 2. Carcinomatosis linfangítica. A y B Corte axial y reconstrucción coronal. Nodularidad del intersticio peribroncovascular y de septos interlobulillares. Nódulos pequeños subpleurales.

engrosamiento de septos interlobulillares (que puede ser liso), nódulos grandes, adenomegalias hiliares/ mediastinales y líquido pleural (4).

\section{Bibliografía}

1. Webb WR, Müller NL, Naidich DP. High Resolution CT of the Lung. Fifth Edition. Lippincott Williams \& Wilkins. 2014;112-16

2. Boitsios G, Bankier AA, Eisenberg RL. Diffuse pulmonary nodules. AJR Am J Roentgenol. 2010;194(5):W354-66.

3. Little BP. Sarcoidosis: overview of pulmonary manifestations and imaging. Semin Roentnol. 2015;50(1):52-64.

4. Aquino SL. Imaging of metastasic disease to the thorax. Radiol Clin N Am. 2005;43:481-95. 